\title{
IMPESSOALIDADE E PASSIVIDADE NOS MANUAIS ACADÊMICOS: IMPLICAÇÕES PARA A CLAREZA NA PESQUISA QUALITATIVA
}

\author{
Paulo de Tarso Oliveira ${ }^{1}$ e Maria Eunice Barbosa Vidal ${ }^{2}$ \\ ${ }^{1}$ Centro Universitário Municipal de Franca - Uni-FACEF, Brasil. paulotarso@facef.br \\ ${ }^{2}$ Universidade Federal do Triângulo Mineiro - UFTM, Brasil. mariaeunice.vidal@uftm.edu.br
}

\begin{abstract}
Resumo. A questão básica deste estudo refere-se a quais papéis podem desempenhar os manuais de elaboração de trabalhos acadêmicos - propostos por instituições universitárias - quanto à comunicação nos relatos científicos, no contexto atual das tendências dinâmicas na construção do conhecimento. Este estudo se justifica em razão da influência que as recomendações estabelecidas pelas instituições universitárias para a redação de trabalhos científicos exercem na produção dos relatos de pesquisa. O objetivo da presente pesquisa é descrever e compreender os padrões de utilização desses materiais, especialmente no tocante às recomendações de características de linguagem a serem seguidas em termos de adequação aos diversos delineamentos possíveis de pesquisa. Sob a égide de pesquisa documental, como viés interpretativista dialético, os dados foram coletados em sites eletrônicos de instituições universitárias diversas, analisados, inicialmente numa fase exploratória e, posteriormente, incluindo manuais de instituições situadas numa região delimitada, abrangendo partes de dois Estados brasileiros. Os resultados apontam uma linguagem acadêmica inflexível, indicada para os relatos científicos, o que pode ser um entrave para uma redação mais clara e atualizada que, em conclusão, pudesse dar a conhecer a presença do pesquisador que, com suas concepções e suas práticas procedimentais, vivifica o conhecimento, principalmente o resultante de pesquisa qualitativa.
\end{abstract}

Palavras-chave: Impessoalidade na Linguagem; Clareza; Relação Sujeito/Objeto; Manuais Universitários; Pesquisa Qualitativa.

\section{IMPERSONALITY AND PASSIVITY IN ACADEMIC MANUALS: IMPLICATIONS FOR CLARITY IN QUALITATIVE RESEARCH}

Abstract. The basic question of this study refers to what roles the manuals for the elaboration of academic works - proposed by university institutions - can play regarding communication in scientific reports, in the current context of dynamic trends in the construction of knowledge. This study is justified due to the influence that the recommendations established by university institutions for writing scientific papers have on the production of research reports. The aim of this research is to describe and understand the patterns of use of these materials, especially with regard to the recommendations of language characteristics to be followed in terms of suitability for the various possible research designs. Under the aegis of documentary research, as a dialectical interpretive bias, data were collected on electronic websites of different university institutions, analyzed initially in an exploratory phase and later, including manuals from institutions located in a defined region, covering parts of two Brazilian states. The results point to an inflexible academic language indicated for scientific reports, which can be an obstacle to a clearer and updated wording that in conclusion, could make known the presence of the researcher who, with his conceptions and procedural practices, vivify knowledge, mainly the resulting of qualitative research.

Keywords: Impersonality in Language; Clarity; Subject/Object Relationship; University Textbooks; Qualitative Research.

\section{INTRODUÇÃO}

O contexto em que se insere o presente artigo é o da discussão de questões referentes à artificialidade do uso, insistentemente proposto, de tratamento impessoal na linguagem dos 
relatos de pesquisa científica em geral e, em especial, nas pesquisas qualitativas. Trabalhando nessa seara, os autores da presente investigação têm estudado a suposição e seus efeitos - de que essa linguagem impessoal pudesse revelar uma isenção do pesquisador como sujeito na apreensão do objeto de estudo. Enfim, a linguagem impessoal entendida como uma forma de manter, nos relatos, a isenção de qualquer contaminação do sujeito-pesquisador sobre o objeto-pesquisado.

Bem inserida nas concepções positivistas, essa noção serviu ao conceito de neutralidade científica e continua forte nos meios acadêmicos, ainda que de forma subentendida. Tal tendência tem sido corroborada em muitas observações oriundas da experiência docente dos autores como professores de metodologia científica no ensino superior, bem como de outras atividades acadêmicas (como pesquisas, leituras e participação em bancas examinadoras de trabalhos acadêmicos de graduação e de pós-graduação). Essa fonte inicial de motivação gerou também interesses pela pesquisa sobre características de linguagem sugeridas para os relatos científicos.

Em seu percurso, essas atividades de investigação geraram indagações diversas. Entre elas - foco do presente estudo - as questões: (i) que implicações pode ter a (in)flexibilidade da linguagem na construção da clareza das demonstrações em pesquisas qualitativas? (ii) que papel representam os manuais de elaboração de trabalhos científicos, propostos pelas instituições universitárias, quanto às características da linguagem a ser utilizada?

Entendemos que o estudo das recomendações que as instituições universitárias propõem, para orientar a redação de trabalhos científicos por parte de seus integrantes, torna-se primordial devido à influência determinante desses materiais na produção dos relatos acadêmicos.

O objetivo estabelecido para este estudo - limitado a uma amostra - é descrever e compreender os padrões de utilização desses materiais, especialmente quanto às recomendações de características de linguagem (impessoalidade, passivização, clareza) a serem seguidas, em termos de adequação aos diversos delineamentos possíveis de pesquisa. Esperamos também que possa contribuir para o desenvolvimento de indicadores para melhor interpretação de dados e para a construção mais acurada de categorias de análise a serem utilizadas em estudo mais amplo. Para tanto, sob a égide de pesquisa documental, foram consultados manuais emanados pelas instituições universitárias constitutivas da amostra. 


\section{REFERENCIAL TEÓRICO}

\subsection{Ciência, objetividade e linguagem}

$\mathrm{Na}$ trajetória do pensamento científico, um marco importante foi que, ao desenvolver uma filosofia positivista, Auguste Comte propôs às ciências sociais e humanas que usassem os mesmos princípios e métodos adotados pelas ciências exatas e, em decorrência, a ideia de que o conhecimento científico poderia ser inteiramente objetivo, livre de quaisquer influências subjetivas. Contudo, essa proposição representou, na pena de estudiosos das ciências sociais, um inaceitável negligenciamento do contexto sócio-histórico.

Morin (2010), por exemplo, fazendo críticas a princípios que norteavam a ciência até a metade do século vinte, menciona, entre eles, a separação sujeito / objeto no sentido de que podemos ter o conhecimento objetivo eliminando a subjetividade. Ressalta que existem projeções das estruturas mentais dos sujeitos no conhecimento objetivo que também é produzido sob condições históricas, sociológicas e culturais precisas. Por conseguinte, emergiu um paradigma alternativo para fazer ciência: o paradigma interpretativista. Decorre daí que a pesquisa qualitativa procura entender e interpretar fenômenos sociais constitutivos de um contexto de que a linguagem é parte.

É preciso que se diga, antes de tudo, que a ciência é um modo de pensar, mais do que um conjunto de conhecimento (Sagan, 1996). Essa ideia pode ser complementada com a posição de Bortoni-Ricardo (2013) ao asseverar a impossibilidade de observar o mundo sem influência das práticas sociais. Para a autora, fica evidenciado principalmente que, em cada época, os significados em vigor estão enraizados na capacidade do observador, cuja compreensão revela um agente ativo e, não, um mero relator passivo. Nesse sentido, já na década de 70, Umberto Eco ressaltava que escrever é um ato social, e quem escreve espera que o leitor aceite aquilo que se Ihe propõe no texto (Eco, 2002).

Afinado com essa concepção, Pinker (2016) considera que procuramos entender o mundo social como constituído de forças, pressões, processos e desenvolvimentos. O autor continua apontando que essas forças são resultado dos feitos de milhões de homens e mulheres que agem a partir de suas crenças em busca de seus desejos. De fato, o hábito de fazer submergir o indivíduo em abstrações pode levar não só a uma ciência ruim, mas também à desumanização. Em adendo, acrescentamos que os fenônemos referentes ao mundo humano 
e social ocorrem numa realidade dinâmica e mutante e não devem ser vistos, nem comunicados, como se fossem fenômenos estáticos da natureza.

\subsection{Impessoalidade, passivização e clareza}

Em um estudo anterior de Oliveira e Vidal (2017), ficou ressaltada a suposição de que o uso da impessoalidade como característica da comunicação científica traz em seu bojo uma tentativa de convencer o leitor de que aquele conhecimento produzido é totalmente objetivo; insista-se, isento de qualquer influência subjetiva. E, portanto, é a verdade sem quaisquer outras influências culturais.

Com efeito, isso pode ser inclusive resultante do entendimento distorcido na leitura de alguns preceitos sobre a linguagem na ciência como, por exemplo: Diehl e Tatim (2006) pontuam que, mesmo cientes de que dificilmente chegaremos à verdade absoluta dos fenômenos analisados, devemos nos esforçar para não nos deixar levar pela subjetividade de posições e opções pessoais. Afora isso, existe na comunidade científica uma espécie de denominador comum ou um senso comum daquilo que pode ou não pode. Nesse sentido, existe uma linguagem científica que alguns autores denominam de jargão. Essa linguagem elimina, além do uso de adjetivação, as preferências individuais e opções pessoais, a fim de não violar a estrutura básica do pensamento científico.

Nesse e noutros exemplos, o evitar a subjetividade refere-se a eventuais distorções que ela possa provocar nos resultados. Não implica que essa subjetividade seja corrigida pela impessoalidade na linguagem dos relatos.

Prolongando e aprofundando essa reflexão, fica realçado que o uso exclusivo da impessoalidade nos relatos científicos tende, a nosso ver, a escamotear dados da realidade e, com isso, acaba prejudicando a clareza. Assim, ao tentar disfarçar ou ao usar a impessoalidade como disfarce de objetividade, o pesquisador pode distorcer os próprios resultados de pesquisa, tornando-os não claros. Cabe aqui o exemplo seguinte: se um autor, ao emitir uma opinião, disser concluo que estará corretamente assumindo que se trata de uma posição pessoal. Porém, se disser conclui-se que, estará, de certa forma, escondendo a autoria e dando a impressão de que é uma afirmação geral.

Dentre os estudiosos que vêm se debruçando sobre o tema da clareza, citamos Vidal (2011) para quem clareza é tradicionalmente conceituada como uma virtude do texto que não deixa 
dúvidas de compreensão em seu destinatário. Fiel a esse conceito, a elaboração de textos inteligíveis deve envolver elementos como considerar o conhecimento que se tem do destinatário, o conhecimento do contexto de interação, a adequação das formas pessoais ou impessoais, ativas e passivas, no relato de fatos e procedimentos realizados. $\mathrm{Na}$ consideração dos fatos e procedimentos observados, pesam negativamente alguns equívocos gramaticais especialmente quando deles resulta a omissão de informações procedimentais relevantes como, por exemplo, a identificação de quem elaborou os instrumentos de coleta, como e em que contexto situacional a realizou. Em muitas dessas situações, requerem-se, portanto, a pessoalidade na linguagem e a voz ativa verbal.

Quase 60 anos, convém lembrar, separam as discussões recentes do original Epistle to thesis writers de autoria do psicólogo social Gordon Allport, em que tece considerações extremamente contundentes àqueles que, por ansiedade e insegurança, são tentados a fazer o uso da voz passiva alegando ser a única alternativa para evitar o uso excessivo do pronome pessoal da primeira pessoa, ou do nós majestático. O autor asseverava: "Tratem de vencer a covardia e comecem o capítulo de conclusões com a asserção criativa: Pronto! Eu achei..." Não vejo nenhum perigo em dizer "eu" quando quero dizer "eu" (Allport citado in Pinker, 2016, p. 72).

Num breve hiato de tempo, porque publicado pela primeira vez em 1977, Eco (2002) também confirma a ideia de que impessoal só para o que é impessoal. De suas concepções se depreende que há casos em que se deve recorrer a expressões mais impessoais, mas que, em diversas situações, o uso de expressões pessoais é válido. E até sugere que, quando o autor de um trabalho expõe opiniões pessoais, deva afirmar julgamos que. De fato, Oliveira e Vidal (2017) admiram-se de quão esdrúxula seria a expressão de um autor, nas circunstâncias de expor uma posição pessoal, usasse julgou-se que, ou na descrição de procedimentos, optasse por elaborou-se um questionário, fez-se uma entrevista (afinal, quem julgou? / quem elaborou? / quem entrevistou?). Em todos esses casos, supomos que a preocupação em tornar impessoal a linguagem acaba por incorrer em um problema grave que é a omissão de informações metodológicas relevantes: quem está fazendo o juízo de valor, quem é o elaborador do questionário, quem realizou as entrevistas.

Do mesmo modo, o papel da flexibilidade na linguagem científica é também ressaltado por Roesch (1999) ao comentar sobre a questão da impessoalidade e passividade na linguagem científica. Em reforço, menciona Alasuutari (1995) que, já há muito, alertava para o problema 
da utilização demasiada da voz passiva que torna o texto por demais impessoal. Assim, defende que o pesquisador pode introduzir variação no texto ao utilizar a primeira pessoa do singular (ou do plural), por exemplo, em partes do relato no qual conta como conduziu o seu estudo. O autor chamou a atenção, na época, para que, embora o uso da primeira pessoa do singular para relatar trabalhos científicos fosse pouco comum, a situação estava mudando, ressalvando, porém, que seu uso tem de servir a uma função.

Nesse particular, Givón (2012), examinando os tipos de passivização em diferentes línguas, parte de uma regra funcional, segundo a qual a passivização significa a promoção em que um não agente é alçado ao papel de tópico principal da oração. É assim que muitas vezes o redator, diante da necessidade de desviar a atenção do leitor para longe do agente de uma ação, encontra na passivização essa possibilidade de modificar a perspectiva de uma cena. $\mathrm{Na}$ essência, o problema com os manuais de elaboração de textos acadêmicos é, pois, que não levam em conta esses propósitos.

De forma complementar, Abreu (2018) lembra um outro motivo para o uso da voz passiva que é o de permitir o descarte dos responsáveis por uma determinada ação, ora por ser redundante explicitá-los, ora por ser comprometedor fazê-lo. Consequentemente, a voz passiva com descarte do agente poderá ser empregada em situações em que se quer proteger a face de quem produziu a ação como, por exemplo, quando há razões éticas.

\section{METODOLOGIA}

\subsection{Aspectos gerais}

A presente pesquisa (como parte de um estudo maior) se faz por uma amostragem de manuais de instituições em regiões delimitadas, quais sejam as situadas num raio aproximado de $200 \mathrm{Km}$ em torno das cidades de Franca, no Estado de São Paulo, e da cidade de Uberaba, no Estado de Minas Gerais. Essa escolha se justifica, primeiramente, porque tais regiões comportam um grande número de instituições universitárias. Outra razão é o interesse por estudos regionalizados, tendo em vista a atuação de um dos autores em Programa de Mestrado em Desenvolvimento Regional. A terceira razão é a que são cidades-sede de docência dos autores desta pesquisa.

Restringe-se ao estudo de textos contidos em manuais de elaboração de trabalhos acadêmicos no âmbito de instituições universitárias. Trata-se, portanto, de pesquisa 
documental. Entendemos aqui documento como "qualquer suporte que contenha informação registrada, formando uma unidade, que possa servir para consulta, estudo ou prova. Inclui impressos, manuscritos, registros audiovisuais e sonoros, imagens, entre outros" (ABNT 2018, p 2). Justifica-se essa modalidade de pesquisa sobretudo quando consideramos, com Flick (2009) que a construção de explicações sobre eventos pode ser feita a partir de documentos entendidos não como contêineres de informação; mas, sim, como instrumentos de contextualização da informação metodologicamente elaborados.

Como se pode verificar, os documentos utilizados, neste recorte, são escritos e disponíveis na forma eletrônica. A sua análise é feita em busca da compreensão dos padrões de sua utilização em seus contextos. Tem como foco as recomendações eventualmente propostas quanto às características da linguagem que devem ser seguidas pelos autores dos relatos e seu questionamento em termos de adequação aos delineamentos dessas pesquisas.

Convém mencionar que, na pesquisa qualitativa, deve ficar clara a inserção do pesquisador no objeto. Tanto as suas motivações, quanto a sua capacidade de observação e compreensão; quanto, ainda, a sua visão de mundo estão presentes na sua investigação, o que leva a uma visão influenciada pelos significados que ele tem incorporados pelas suas práticas sociais.

Vale aqui a observação de Bortoni-Ricardo (2013, p. 32) de que o pesquisador "não é um relator passivo, mas um agente ativo". Esses aspectos todos carecem de ser levados em conta, tendo em vista que a metodologia concentra-se na interpretação que busca entender fenômenos humanos observados em um determinado contexto sociocultural.

Nesse sentido, é forçoso acrescentar que a análise interpretativa documental - metodologia que responde bem à questão desta investigação - às vezes é permeada por dados observacionais compilados pelos autores. Todos convergentes para o foco na questão de qual linguagem ou de que caracterísitcas de linguagem são as mais adequadas para o relato de pesquisas qualitativas.

Consideramos esses procedimentos como bastante significativos para a presente investigação. Autores como, por exemplo, Erickson (1990), Bortoni-Ricardo (2013), entre outros, lembram que a importância dos procedimentos de observação, no contexto vivencial dos investigadores, tem sido ressaltada com intuito de captar significados atribuídos pelas pessoas no âmbito em geral da sociedade e, em especial, nos nichos ou contextos de trabalho 


\subsection{Coleta de dados}

Os dados constantes desse relato, conforme já mencionado, foram coletados em sites eletrônicos de instituições universitárias, seguindo os seguintes passos. Primeiro passo: preliminarmente, a título exploratório, foram consultados, de forma aleatória, sites de algumas instituições de ensino superior, observando os manuais delas emanados, atualizados a partir de 2017. Foram, então, consultados, naquele primeiro momento, os sites das seguintes instituições: Faculdade de Ciências Humanas de Curvelo (FACIC); Universidade de Caxias do Sul (UCS); Universidade Federal de Minas Gerais (UFMG); Universidade Estadual de Campinas (UNICAMP); Universidade Vale do Rio Verde de Três Corações (UNINCOR); Universidade do Vale do Rio dos Sinos (UNISINOS); Universidade do Oeste Paulista (UNOESTE); Universidade Federal de Uberlândia (UFU); Universidade de São Paulo Enfermagem (USP).

O conteúdo desses manuais foi verificado quanto à orientação de uso da linguagem nos trabalhos acadêmicos. Nessa fase inicial, observamos muitas reproduções, excertos; enfim, compilações de normas da ABNT. Nesses materiais, há alguns que não fazem menção ao estilo de linguagem a ser usado; em outros encontramos recomendações como Procure escrever os textos na terceira pessoa...; Elementos textuais: texto redigido na terceira pessoa do singular...; e outro, ainda, que delega tal função aos orientadores. Há também menções à objetividade e clareza.

Segundo passo: de posse desses dados mais gerais, procuramos propor os aspectos do conteúdo a serem observados, agrupados em categorias, inicialmente, assim estabelecidas: (i) recomendação de objetividade na linguagem; (ii) recomendação de impessoalidade na linguagem; (iii) recomendação de clareza na linguagem; (iv) recomendação de uso do verbo na voz ativa e na terceira pessoa do singular no texto completo; (v) recomendação de uso do verbo na voz ativa e na terceira pessoa do singular somente no resumo; (vi) nenhuma recomendação sobre caracterísitcas de linguagem.

Igualmente, nesse momento, procuramos proceder à composição da amostra, escolhendo instituições significativas na região e estruturadas sob a forma de universidades e centros universitários, tanto do Estado de São Paulo quanto de Minas Gerais. Ao todo, seis universidades, e cinco centros universitários: (A) Universidade de São Paulo (USP); (B) Universidade de Ribeirão Preto (UNAERP); (C) Universidade Estadual Paulista (UNESP); (D) Universidade Federal do Triângulo Mineiro (UFTM); (E) Universidade de Uberaba (UNIUBE); 
(F) Centro Universitário Municipal de Franca (UNIFACEF); (G) Centro Universitário Barão de Mauá (UNIMAUÁ); (H) Centro Universitário Moura Lacerda (MOURA LACERDA); (I) Centro Universitário de Araguari (IMEPAC); (J) Centro Universitário de Araxá (UNIARAXÁ); (K) Universidade Estadual de Minas Gerais (UEMG). Ao todo foram, portanto, consultados 11 (onze) manuais que constituíram a amostra, com exclusão das faculdades isoladas, previstas para inclusão numa continuidade futura da pesquisa. Cumpre esclarecer que entre o primeiro levantamento de dados e esta presente versão, três institituições deixaram de disponibilizar os manuais em seus sites, razão pela qual foram substituídas. Nessa continuidade, está prevista a inclusão de outros pesquisadores, além dos dois autores do presente trabalho.

\subsection{Dados e sua discussão}

Para efeito de análise, os dados foram organizados em dois blocos distintos. Um deles engloba aspectos das normas da Associação Brasileira de Normas Técnicas (ABNT), uma vez que elas estabelecem parâmetros gerais para trabalhos acadêmicos no Brasil. Em outro bloco, são analisados dados constantes dos manuais disponibilizados nos sites das instituições, segundo as categorias estabelecidas para a análise.

\section{- Quanto às normas da Associação Brasileira de Normas Técnicas (ABNT):}

As normas técnicas para a formatação de trabalhos acadêmicos e que servem de referência para os manuais emanados das instituições universitárias são: ABNT-NBr 14724 (2011), que estabelece a estrutura dos trabalhos acadêmicos e regras para formatação; ABNT-NBr 10520 (2002), que fixa regras para citações em textos acadêmicos; ABNT-NBr 6023 (2018), que regulamenta a elaboração da lista de referências bibliográficas; ABNT-NBr 6027 (2012)que estabelece a forma de construir os sumários; e ABNT-NBr 6028 (2003), que normatiza a elaboração do resumo nos trabalhos acadêmicos.

As normas nada trazem de recomendação de detalhes de linguagem, com exceção da norma ABNT-NBr 6028 que normatiza a elaboração do resumo em trabalhos acadêmicos. Nela encontramos uma referência mais detalhada acerca da linguagem, recomendando que "devese usar o verbo na voz ativa e na terceira pessoa do singular".

Entretanto, cabe aqui salientar que essa norma é específica para a elaboração de resumos de trabalhos acadêmicos. Por um lado, trata-se, em suma, de uma estrutura de parágrafo único, no qual se expõe a visão panorâmica de uma pesquisa, sem detalhamento de 
procedimentos. Por outro lado, pode ser que essa recomendação se justificaria pelo fato de que o resumo é uma síntese, cujo foco é a pesquisa e, não, a autoria. Ainda assim, dada a ampla variedade de pesquisas, especialmente as qualitativas, essa regra passa a ser questionável, uma vez essa recomendação pode ser vista como decorrente de suposição de que o uso de outras flexões verbais fora da terceira pessoa do singular, bem como o uso da passivização possam violar a estrutura básica do pensamento científico, preocupações essas que foram tanto descritas quanto criticadas por Diehl e Tatim (2006). Mais ainda quando a sua aceitação é estendida para todos os elementos textuais, o que pode criar problemas para a clareza do texto. Reiteramos, no entanto, que não há nenhum dispositivo que estenda a recomendação dessa norma para o texto integral do trabalho acadêmico.

\section{- Quanto aos manuais disponibilizados nos sites estudados:}

Os conteúdos dos manuais, no tocante às recomendações de linguagem foram catalogados e agrupados em categorias e, nelas, se distribuíram conforme a tabela abaixo:

Tabela 1. Recomendações de uso de caracterísitcas de linguagem nos manuais

\begin{tabular}{lc}
\hline CATEGORIAS & INSTITUIÇÕES/MANUAIS \\
\hline (i) recomendação de objetividade na linguagem & $\mathrm{B}-\mathrm{G}-\mathrm{I}-\mathrm{k}$ \\
(ii) recomendação de impessoalidade na linguagem & $\mathrm{I}-\mathrm{K}$ \\
(iii) recomendação de clareza na linguagem & $\mathrm{B}-\mathrm{G}-\mathrm{K}$ \\
(iv) verbo na voz ativa e na terceira pessoa do singular no texto & $\mathrm{K}$ \\
completo & $\mathrm{B}-\mathrm{D}-\mathrm{E}-\mathrm{F}-\mathrm{H}-\mathrm{I}-\mathrm{J}-$ \\
(v) verbo na voz ativa e na terceira pessoa do singular no resumo & $\mathrm{K}$ \\
(vi) nenhuma recomendação sobre características de linguagem & $\mathrm{A}-\mathrm{C}$ \\
\hline
\end{tabular}

Verificamos na primeira categoria (i) que a objetividade na linguagem é ressaltada em quatro manuais (B; G; I; K). Nenhum desses documentos explica o que pretendem dizer com a palavra objetividade ou linguagem objetiva. Na categoria (ii) aparecem dois manuais (I; K) a recomendar a impessoalidade, um deles (I) mencionando especialmente neutralidade científica. Na terceira categoria (iii), figuram três manuais (B; G; K), sendo que, em G e K, ocorre a imposição da clareza como qualidade textual sem conceituação. $E$ apenas um manual $(K)$ esclarece o seu significado. Clareza é um conceito bastante complexo e parece que a menção a ela, sem explicação, pode sinalizar um desconhecimento de sua natureza que inclui, entre outros fatores, o conhecimento do contexto e a adequação das formas pessoais ou impessoais, ativas e passivas, conforme estudos já mencionados (Vidal, 2011). 
Na categoria (iv) - recomendação de uso de verbo na voz ativa e na terceira pessoa do singular, para todo o texto dos trabalhos - aparece um dos manuais $(\mathrm{K})$ : faz a recomendação de uso geral da voz ativa, desconsiderando, desse modo, funções discursivas importantes desempenhadas pela famigerada voz passiva no contexto sociocomunicativo, já elucidadas como, por exemplo, em Givon (2012) e Abreu (2018).

A categoria $(v)$ contemplou as menções de uso do verbo na voz ativa e na terceira pessoa do singular, somente no resumo, na qual aparecem oito manuais (B; D; E; F; H; I; J; K) que a recomendam. Essas menções certamente ocorrem por reproduzir norma da ABNT destinada à redação de resumos.

$\mathrm{Na}$ categoria (vi), aparecem dois manuais $(\mathrm{A} ; \mathrm{C})$ que nada mencionam sobre exigências de características de linguagem. Uma das possibilidades de interpretação decorrente é que essas instituições dão liberdade de redação, o que significa permitir a flexibilização da linguagem. Podemos considerar isso, em parte, como positivo; mas talvez fosse melhor, no contexto atual, que indicassem a flexibilidade como algo recomendável, no sentido de que o que é impessoal deva ser expresso como impessoal, mas não cabe expressão impessoal para o que seja pessoal - a exemplo de procedimentos, ilações e julgamentos, no contexto das pesquisas qualitativas.

Dado que poucos manuais recomendam a impessoalidade e o demais omitem a flexibilização da linguagem, pode-se considerar que reforcem a permanência do preconceito da neutralidade no cotidiano acadêmico. As ditas recomendações, por estenderem, explicita ou subentendidamente, características de linguagem impessoal para a íntegra dos textos; a omissão, por deixar um vácuo de esclarecimentos mais atualizados sobre o uso da linguagem nos relatos.

Seria o caso, então, de levantar questionamentos: se as orientações postas pelas instituições de ensino superior não propõem a impessoalidade, em sua maioria, - e igualmente os manuais de metodologia disponíveis - como essa crença vesga está sobrexistindo? Seria a tradição oral que está fazendo essa persistência com mais força que a produção escrita? Qual é a força dessa tradição em reproduzir essas crenças na população universitária atual? Quais as ligações com outras recomendações costumeiras em manuais de metodologia e redação de trabalhos acadêmicos? 
Decerto, essas questões, postas como estão, levam a crer que isso tudo é relevante para norteamento da comunicação de pesquisa, especialmente quando se constata o avanço da pesquisa qualitativa em ciências humanas e sociais no mundo acadêmico.

\section{CONCLUSÕES}

A questão central de investigação desta pesquisa destacou o papel que manuais de elaboração de trabalhos acadêmicos pode desempenhar na construção do conhecimento em termos de clareza nos relatos científicos, levando em conta tendências atuais no campo da Linguística e da pesquisa qualitativa.

O estudo que recaiu sobre manuais disponibilizados nos sites de instituições de ensino superior foi norteado a partir de concepções teóricas atuais dos autores estudados sobre a relação sujeito / objeto no conhecimento humano, bem como quanto às expressões adequadas sobre o uso da (im)pessoalidade no discurso científico.

Pelos dados que acabamos de discutir, é lícito supor que a inflexibilidade na linguagem sugerida para os relatos acadêmicos podem configurar como um dos principais entraves para a construção de uma redação mais condizente com as tendências do pensamento atual, sobretudo no que se refere à pesquisa qualitativa.

Assim se considerando, parece razoável afirmar que manuais desavisados em matéria de Linguística acabam se revelando pouco flexíveis acerca da linguagem em uso; e outros por não esclarecerem termos como clareza, objetividade e legitimidade da voz passiva, comprometem a coerência lógica e a clareza das ideias. Vale considerar também que questões surgidas a partir dos dados da presente investigação, como a referente aos fatores associados à permanência da ilusão de neutralidade, via linguagem, são relevantes para gerarem novas pesquisas. Pode-se dizer, também, que o instrumental desenvolvido para a catalogação e análise dos dados, a par de mostrar-se útil ao presente estudo, pode servir para aplicação na continuidade da pesquisa.

Cabe aqui a ressalva de que os resultados a que chegamos, embora compatíveis com a posição de vários teóricos, não podem ser generalizados para além do âmbito em que foram obtidos. Apesar disso, não nos parece descabido defender que os resultados poderão, ainda que modestamente, contribuir para ajustar características de linguagem às peculiaridades da 
pesquisa qualitativa, tendo em vista a sua expressão cada vez maior na produção do conhecimento no mundo de hoje.

\section{REFERÊNCIAS}

Abreu, A. S. (2018). Gramática integral da língua portuguesa: uma visão prática e funcional. Cotia-SP: Ateliê Editorial.

Alasuutari, P. (1995). Researching culture: qualitative method an cultural studies. Londres: Sage.

Associação Brasileira de Normas Técnicas. (2018). NBR 6023: informação e documentação - referências elaboração. Rio de Janeiro: ABNT.

Associação Brasileira de Normas Técnicas. (2012). NBR 6027: informação e documentação - sumário apresentação. Rio de Janeiro: ABNT.

Associação Brasileira de Normas Técnicas. (2003). NBR 6028: informação e documentação - resumo apresentação. Rio de Janeiro: ABNT.

Associação Brasileira de Normas Técnicas. (2002). NBR 10520: informação e documentação - citações em documentos - apresentação. Rio de Janeiro: ABNT.

Associação Brasileira de Normas Técnicas. (2011). NBR 14724: informação e documentação - trabalhos acadêmicos - apresentação. Rio de Janeiro: ABNT.

Bortoni-Ricardo, S. M. (2013). O professor pesquisador: introdução à pesquisa qualitativa. São Paulo: Parábola.

Diehl, A. A.; Tatim, D. C. (2004). Pesquisa em ciências sociais aplicadas: métodos e técnicas. São Paulo: Pearson Prentice Hall.

Eco, U. (2002). Como se faz uma tese. Tradução Gilson Cesar Cardoso de Souza. São Paulo: Perspectiva.

Erickson, F. (1990). Qualitative methods. Research in teaching and learning. York: Macmillan Company.

Flick, U. (2009). Introdução à pesquisa qualitativa. (3a ed.). Porto Alegre: Artmed.

Givón, T. (2012). A compreensão da gramática. Tradução Maria Angélica Furtado da Cunha, Mário Eduardo Martelotta, Filipe Albani. São Paulo: Cortez; Natal-RN: EDUFRN.

Morin, E. (2010). Saberes globais e saberes locais: o olhar transdisciplinar. Rio de Janeiro: Garamond.

Oliveira, P. T., \& Vidal, M. E. B. (2017). O mito da neutralidade científica e o uso da linguagem impessoal. In Atas do $6^{\circ}$ congresso ibero-americano em investigação qualitativa: investigação qualitativa na educação, v. 1 (pp. 332-336). Aveiro, Portugal: Ludomedia.

Pinker, S. (2016). Guia de escrita: como conceber um texto com clareza, precisão e elegância. Tradução Rodolfo llari. São Paulo: Contexto.

Roesch, S. M. A. (1999). Projetos de estágio e de pesquisa em administração: guias para estágios, trabalhos de conclusão, dissertações e estudos de casos. São Paulo: Atlas.

Sagan, C. (1996). O mundo assombrado pelos demônios: a ciência vista como uma vela no escuro. Tradução Rosaura Eichemberg. São Paulo: Companhia das Letras.

Vidal, M. E. B. (2011). A construção do sentido na escrita de alunos universitários: uma proposta de ensino fundamentada nos princípios cognitivos de adaptação e complexidade. Tese (Doutorado em Linguística e Língua Portuguesa não publicada). Universidade Estadual Paulista (UNESP). Araraquara-SP.

\section{Sites Consultados:}


Centro Universitário de Araxá. Manual de normalização para apresentação de trabalho científico. https://www.uniaraxa.edu.br/assets/pdf/2019/manual-de-normalizacao-2019.pdf

Centro Universitário Municipal de Franca. Estrutura e formatação de trabalhos acadêmicos. Recuperado de https://www.unifacef.com.br/wp-content/uploads/2019/07/e-book-Estrutura-e-Formata\%C3\%A7\%C3\%A3ode-Trabalhos-Acad\%C3\%AAmicos.pdf

Centro Universitário IMEPAC Araguari. Guia para normalização de trabalhos acadêmicos e científicos. Recuperado de https://imepac.edu.br/wp-content/uploads/2020/03/Guia-para-normaliza\%C3\%A7\%C3\%A3o-detrabalhos-acad\%C3\%AAmicos-e-cient\%C3\%ADficos-2020-Revis\%C3\%A3o-2-1.pdf

Centro Universitário Barão de Mauá. Orientação na normalização de trabalhos técnico-científicos. Recuperado de https://www.baraodemaua.br/biblioteca.

Centro Universitário Moura Lacerda. Manual de normas metodológicas. Recuperado de https://www.portalmouralacerda.com.br/wpcontent/uploads/2020/02/NORMASMETODOLOGICAS_140220. pdf

Universidade de Uberaba. (2019). Manual de normatização. Recuperado de https://www.uniube.br/biblioteca/novo/arquivos/2019/manual_normatizacao2019.pdf

Universidade Federal do Triângulo Mineiro. (2019). Manual para apresentação de trabalhos acadêmicos. Recuperado de http://www.uftm.edu.br/biblioteca/manual-para-apresentacao-de-trabalhos-academicos

Universidade de Ribeirão Preto. (2015). Manual de apresentação de trabalhos acadêmicos. Recuperado de https://www.unaerp.br/documentos/1342-manual-para-apresentacao-de-trabalho-cientifico-2014/file

Universidade de São Paulo. (2017). Diretrizes para apresentação de dissertações e teses da USP. Recuperado de http://www.livrosabertos.sibi.usp.br/portaldelivrosUSP/catalog/view

Universidade Estadual de Minas Gerais (2017). Manual para elaboração e normalização de trabalhos acadêmicos e técnico-científicos da ED-UEMG. Recuperado de http://eduemg.uemg.br/images/livros-pdf/catalogo2017/2017_EDD_Manualmonografia.pdf

Universidade Estadual Paulista. (2019). Orientações para apresentação de trabalhos acadêmicos. Recuperado de https://www.franca.unesp.br/Home/Biblioteca_N/orientacoes-para-apresentacao-de-trabalhosacademicos.pdf 